\title{
JNPH
}

Volume 7 No. 1 (April 2019)

(C) The Author(s) 2019

\section{HUBUNGAN DUKUNGAN KELUARGA DENGAN KUALITAS HIDUP PENDERITA TBC DI KECAMATAN SELEBAR KOTA BENGKULU TAHUN 2018}

\section{RELATIONSHIP OF FAMILY SUPPORT WITH THE QUALITY OF LIFE OF TBC PATIENTS IN SELEBAR DISTRICT, BENGKULU CITY IN 2018}

\author{
EFRIZON HARIADI ${ }^{1}$, FENTI ARYANI ${ }^{2}$, ERNI BUSTON ${ }^{3}$ \\ POLITEKNIK KESEHATAN KEMENKES BENGKULU ${ }^{1,3}$ \\ PUSKESMAS JEMBATAN KECIL KOTA BENGKULU ${ }^{2}$ \\ Email: efrizonhariadi77@gmail.com
}

\begin{abstract}
ABSTRAK
TBC adalah penyebab kematian kesembilan di seluruh dunia dan penyebab utama dari satu agen infeksius. TBC dapat memperlemah fungsi fisik penderita dan menganggu kualitas hidup mereka. Asuhan pada penderita diterapkan dengan melibatkan keluarga sebagai pemberi perawatan langsung pada anggota keluarga dengan TBC. Penelitian ini bertujuan untuk mengetahui hubungan dukungan keluarga dengan kualitas hidup penderita TBC di Kecamatan Selebar Kota Bengkulu Tahun 2018. Desain penelitian cross-sectional. Sampel penelitian adalah penderita TBC sebanyak 50 orang. Hasil penelitian terhadap variabel dukungan keluarga menunjukkan ada hubungan yang bermakna dengan nilai $p$ value $0,03(p<0,05)$ terhadap kualitas hidup penderita TBC di Kecamatan Selebar Kota Bengkulu. Dukungan keluarga merupakan unsur yang terpenting dalam individu menyelesaikan masalah. Dukungan keluarga akan menambah rasa percaya diri dan memotivasi untuk menghadapi masalah dan meningkatkan kepuasan hidup, keluarga merupakan support sistem utama bagi penderita TBC dalam mempertahankan kesehatannya, keluarga merupakan support sistem utama bagi penderita TBC dalam mempertahankan kesehatannya.
\end{abstract}

Kata Kunci: TBC, Keluarga dan Kualitas Hidup

\begin{abstract}
Tuberculosis is the number 9 cause of mortality and the most infectious agent in the world, estimated that there are 1,3 million death in 2016. At the year of 2015 recorded that any 18.982 tuberculosis case suspect in Bengkulu province and there are 633 suferer spread in all Bengkulu city districts (2017). Tuberculosis weaken the patient body function and disrupt their quality of life. Moreover, many of suferer reported indicate of negative affects such as anxiety and fearness. It also impact to family, community and country. Nursing care for tuberculosis patient applied by involving their family member as caregiver. This research aimed to know the corellation of family support to patient quality of life in selebar district of Bengkulu city the year of 2018. This research design is cross-sectional with Sample of 50 tuberculosis patient and Sampling method is purposive sampling. Data analysis by univariate and bivariate. The result show that there is corellation between family support and tuberculosis patients quality of life ( $p$ $=0,03)$. Family support is the most important element in solving individual problems. Family
\end{abstract}


support will increase self-confidence and motivate to face problems and increase life satisfaction, the family is the main support system for TB patients in maintaining their health, the family is the main support system for TB patients in maintaining their health.

\section{Keywords: Tuberculosis, family, quality of life}

\section{PENDAHULUAN}

Tuberkulosis (TBC) adalah penyakit menular yang diakibatkan oleh Mycobacterium Tuberculosis. Gejala utama TBC adalah batuk berdahak selama 2-3 minggu atau lebih yang tidak jelas penyebabnya. Gejala tambahan yang sering dijumpai pada penderita TBC adalah batuk berdahak bercampur darah, batuk darah, sesak nafas, rasa nyeri dada, badan lemah, malaise, berkeringat di malam hari walaupun tanpa kegiatan, demam meriang lebih dari sebulan (Kemenkes \& IDI, 2012). Penyakit TBC biasanya mengenai paru, namun juga dapat mengenai organ lain. Penularannya melalui udara yaitu dari droplet yang dihasilkan oleh penderita TBC paru aktif (Depkes, 2006).

Menurut Global Tuberculosis Report 2017, TBC adalah penyebab kematian kesembilan di seluruh dunia dan penyebab utama dari satu agen infeksius, peringkat di atas HIV/AIDS. Pada tahun 2016, diperkirakan ada 1,3 juta kematian TBC di antara orang HIV-negatif (turun dari 1,7 juta pada tahun 2000) dan tambahan 374.000 kematian di antara orang HIV-positif. Diperkirakan 10,4 juta orang jatuh sakit dengan TBC pada tahun 2016: 90\% adalah orang dewasa, $65 \%$ adalah laki-laki, 10\% adalah orang yang hidup dengan HIV (74\% di Afrika) dan 56\% berada di lima negara: India, Indonesia, Cina, Filipina dan Pakistan. TBC yang resistan terhadap obat (MDR-TB) adalah ancaman terus-menerus, diperkirakan mencapai 490.000 orang dengan 110.000 kasus yang rentan terhadap isoniazid dan resisten terhadap riampisin.

Ada 3 faktor utama yang menyebabkan tingginya kasus TBC di Indonesia, yaitu, a) waktu pengobatan TBC yang relatif lama (6-8 bulan) menjadi penyebab penderita $\mathrm{TBC}$ sulit sembuh karena pasien TBC berhenti berobat (drop out) setelah merasa sehat meskipun proses pengobatan belum selesai; b) adanya peningkatan infeksi HIV/AIDS yang berkembang cepat dan munculnya permasalahan TB-MDR (Multi Drugs Resistant $=$ kebal terhadap bermacam obat) yang memperberat masalah $\mathrm{TBC}$; dan c) adanya penderita TBC laten, dimana penderita tidak sakit namun akibat daya tahan tubuh menurun, penyakit TBC akan muncul (Dirjen P2PL, 2011).

Berdasarkan data profil Dinas Kesehatan Provinsi Bengkulu tahun 2015, tercatat sebanyak 18.982 suspek TBC. Dari hasil pemeriksaan diketahui ada sebanyak 1.379 $\mathrm{TBC}+$ dan diobati sebanyak 1.538 dengan kesembuhan sebanyak 1.267 (82\%) penderita. Dari data program TB Dinas Kesehatan Kota Bengkulu penderita TBC Tahun 2017 sebanyak 633 penderita yang tersebar di seluruh kecamatan di Kota Bengkulu. Kasus TBC terbanyak di Kecamatan Selebar sebesar 110 penderita. Kecamatan Selebar terdiri dari 2 Puskesmas induk yaitu puskesmas Betungan sebesar 33 penderita dan Puskesmas Basuki Rahmat sebesar 66 penderita.

Louw dkk (2012) membuat kesimpulan dalam penelitian mereka bahwa TBC dapat memperlemah fungsi fisik penderita dan menganggu kualitas hidup mereka. Bahkan banyak penderita TBC dilaporkan mengalami emosi yang negatif seperti cemas dan ketakutan (Guo, Marra \& Marra, 2009). Oleh karena stigma terhadap TBC, mayoritas penderita gagal mengenali gejala yang disebabkan oleh TBC dan mengira itu adalah malaria dan batuk biasa. Setelah diagnosa diketahui, kebanyakan dari penderita TBC merasa keluarga dan teman menghindar dan menjauh. Penyakit TBC juga berdampak pada keluarga, masyarakat maupun negara. Pada skala global dan negara, dampak penyakit 
TBC menjadi beban dunia yang tergambar dalam parameter MDGs (WHO, 2013).

Maglaya (2009) menyebutkan bahwa pelaksanaan tugas kesehatan keluarga dalam menentukan masalah perawatan kesehatan keluarga berkaitan dengan kondisi atau masalah kesehatan yang spesifik. Lima tugas kesehatan keluarga tersebut yaitu, mampu mengenal masalah kesehatan, mampu mengambil keputusan tepat untuk mengatasi kesehatannya, mampu melakukan tindakan keperawatan untuk anggota keluarga yang memerlukan bantuan keperawatan, mampu memodifikasi lingkungan sehingga menunjang upaya peningkatan kesehatan, dan mampu memanfaatkan sarana pelayanan kesehatan yang ada.

Asuhan pada individu dengan TBC diterapkan dengan melibatkan keluarga sebagai pemberi perawatan langsung pada anggota keluarga dengan TBC. Keluarga memberikan perawatan kepada penderita TBC tidak terlepas dari pelaksanaan pelayanan kesehatan keluarga yang harus dijalankan oleh keluarga untuk meningkatkan kualitas hidup anggota keluarga. Penelitian ini bertujuan untuk mengetahui hubungan dukungan keluarga dengan kualitas hidup penderita TBC di Kecamatan Selebar Kota Bengkulu.

Penelitian ini bertujuan untuk mengetahui hubungan antara dukungan keluarga dengan kualitas hidup penderita TBC di Kecamatan Selebar Kota Bengkulu Tahun 2018.

\section{METODE PENELITIAN}

Jenis penelitian yang dilakukan bersifat kuantitatif dengan desain deskriptif korelasional yaitu menguji hubungan antara variabel dengan pendekatan cross-sectional. Populasi dalam penelitin ini adalah Pasien TB paru yang terdaftar di register TB puskesmas se-Kecamatan Selebar bulan Januari sampai dengan Oktober 2018 berjumlah 57 orang. Instrumen penelitian menggunakan kuesioner. Analisa data secara univariat dan bivariat dengan menggunakan uji chi-square pada $\alpha$
$5 \%$.

\section{HASIL}

\section{Analisa Univariat}

Data kualitas hidup penderita TBC dalam penelitian yang dilakukan berdasarkan Survey Short Form (SF-8) pada 50 penderita TBC berusia 18-59 tahun yang masih pada fase pengobatan intensif 2 bulan di Kota Bengkulu. Data kualitas hidup penderita TBC dapat di lihat dari tabel di bawah ini.

\section{Tabel 1. Distribusi frekuensi kualitas hidup penderita TBC Skala Fisik di Kecamatan Selebar Kota Bengkulu Tahun 2018}

\begin{tabular}{cccc}
\hline No & $\begin{array}{l}\text { Kualitas Hidup } \\
\text { Penderita TBC }\end{array}$ & Jumlah & Persentase \\
\hline 1 & Rendah & 22 & 44 \\
\hline 2 & Tinggi & 28 & 56 \\
\hline
\end{tabular}

Dari tabel diatas menunjukkan bahwa kualitas hidup penderita TBC skala fisik di Kecamatan Selebar Kota Bengkulu dengan kategori rendah sebanyak 22 orang (44\%) dan kategori Tinggi sebanyak 28 orang $(56 \%)$ sehingga sebagian besar penderita TBC di Kecamata selebar Kota Bengkulu dengan kualitas hidup tinggi.

\section{Tabel 2. Distribusi kualitas hidup penderita TBC Skala Mental di Kecamatan Selebar Kota Bengkulu Tahun 2018}

\begin{tabular}{cccc}
\hline No & $\begin{array}{c}\text { Kualitas Hidup } \\
\text { Penderita TBC }\end{array}$ & Jumlah & Persentase \\
\hline 1 & Rendah & 25 & 50 \\
\hline 2 & Tinggi & 25 & 50 \\
\hline
\end{tabular}

Dari tabel diatas menunjukkan bahwa kualitas hidup penderita TBC skala mental di Kecamatan Selebar Kota Bengkulu dengan kategori rendah sebanyak 25 orang (50\%) dan kategori Tinggi sebanyak 25 orang $(50 \%)$ sehingga kualitas hidup skala mental sama antara kategori rendah dan tinggi. 
Tabel 3. Distribusi dukungan keluarga penderita TBC di Kecamatan Selebar Kota Bengkulu Tahun 2018

\begin{tabular}{cccc}
\hline No & $\begin{array}{c}\text { Dukungan } \\
\text { Keluarga }\end{array}$ & Jumlah & Persentase \\
\hline 1 & Kurang & 22 & 44 \\
\hline 2 & Baik & 28 & 56 \\
\hline
\end{tabular}

Tabel diatas menunjukkan bahwa dukungan keluarga penderita TBC di Kecamatan Selebar Kota Bengkulu dengan dukungan kurang sebanyak 22 keluarga (44\%) dan dengan dukungan baik sebanyak 28 keluarga (56\%), sehingga dukungan keluarga penderita TBC di Kecamatan Selebar Kota Bengkulu adalah sebagaian besar mendukung untuk proses kesembuhan anggota keluarganya sedang menderita penyakit TBC.

\section{Analisa Bivariat}

Untuk mengetahui apakah variabel independen berhubungan dengan variabel dependen, maka dilakukan analisa bivariat dengan menggunakan uji statistik Chi-square pada variabel dukungan keluarga, dengan hasil sebagai berikut :

Tabel 4. Distribusi dukungan keluarga dengan kualitas hidup penderita TBC dalam skala fisik di Kecamatan Selebar Kota Bengkulu Tahun 2018

\begin{tabular}{|c|c|c|c|c|c|c|c|c|}
\hline \multirow{3}{*}{$\begin{array}{c}\text { Dukungan } \\
\text { Keluarga }\end{array}$} & \multicolumn{4}{|c|}{ Kualitas Fisik } & \multirow{2}{*}{\multicolumn{2}{|c|}{ Total }} & \multirow{3}{*}{$\begin{array}{c}\text { OR } \\
(95 \% \\
\text { CI })\end{array}$} & \multirow{3}{*}{$\begin{array}{c}\text { P Va- } \\
\text { lue }\end{array}$} \\
\hline & \multicolumn{2}{|c|}{ Rendah } & \multicolumn{2}{|c|}{ Tinggi } & & & & \\
\hline & $\mathrm{n}$ & $\%$ & $\mathrm{n}$ & $\%$ & $\bar{n}$ & $\%$ & & \\
\hline & 14 & 63.6 & 8 & 36.4 & 22 & 44.0 & 4,375 & 0,028 \\
\hline \multirow[t]{2}{*}{ Baik } & 8 & 28.6 & 20 & 71.4 & 28 & 56.0 & \multicolumn{2}{|l|}{$\begin{array}{l}(1,325- \\
14,446)\end{array}$} \\
\hline & 22 & 44.0 & 28 & 56.0 & 50 & 100 & & \\
\hline
\end{tabular}

Dari tabel diatas dapat dijelaskan bahwa hasil penelitian terhadap variabel dukungan keluarga menunjukkan ada hubungan yang bermakna dengan nilai $p$ value $0,028(p<0,05)$ terhadap kualitas hidup penderita TBC dalam skala fisik di Kecamatan Selebar Kota Bengkulu.
Tabel 5. Distribusi dukungan keluarga penderita TBC dalam skala mental di Kecamatan Selebar Kota Bengkulu Tahun 2018

\begin{tabular}{|c|c|c|c|c|c|c|c|c|}
\hline \multirow{3}{*}{$\begin{array}{c}\text { Dukungan } \\
\text { Keluarga }\end{array}$} & \multicolumn{4}{|c|}{ Kualitas Mental } & \multirow{2}{*}{\multicolumn{2}{|c|}{ Total }} & \multirow{3}{*}{$\begin{array}{c}\text { OR } \\
(95 \\
\% \\
\text { CI })\end{array}$} & \multirow{3}{*}{$\begin{array}{c}\mathrm{P} \\
\text { Val- } \\
\text { ue }\end{array}$} \\
\hline & \multicolumn{2}{|c|}{ Rendah } & \multicolumn{2}{|c|}{ Tinggi } & & & & \\
\hline & $\mathrm{n}$ & $\%$ & $\mathrm{n}$ & $\%$ & $\mathrm{n}$ & $\%$ & & \\
\hline Kurang & 15 & 68,2 & 7 & 31,8 & 22 & $\begin{array}{c}44 . \\
0\end{array}$ & $\begin{array}{c}4,37 \\
5\end{array}$ & $\begin{array}{c}0,04 \\
6\end{array}$ \\
\hline Baik & 10 & 35,7 & $` 18$ & 64,3 & 28 & $\begin{array}{c}56 . \\
0\end{array}$ & $\begin{array}{c}(1,32 \\
5- \\
14,4 \\
46)\end{array}$ & \\
\hline & 25 & $50 \%$ & 25 & 50 & 50 & 100 & & \\
\hline
\end{tabular}

Dari tabel diatas dapat dijelaskan bahwa hasil penelitian terhadap variabel dukungan keluarga menunjukkan ada hubungan yang bermakna dengan nilai $p$ value $0,046(p<0,05)$ terhadap kualitas hidup penderita TBC dalam skala mental di Kecamatan Selebar Kota Bengkulu.

\section{PEMBAHASAN}

Keluarga adalah dua orang atau lebih yang diikat oleh suatu hubungan emosional yang saling bergantung satu dengan yang lainnya dan merupakan wadah sebagai pengembangan nilai-nilai kesehatan dan kebiasaan sehat. Keluarga merupakan unit terkecil dari masyarakat, jika salah satu anggota keluarga bermasalah terhadap kesehatannya pasti akan mempengaruhi fungsi keluarga. Dukungan keluarga merupakan unsur yang terpenting dalam individu menyelesaikan masalah. Dukungan keluarga akan menambah rasa percaya diri dan memotivasi untuk menghadapi masalah dan meningkatkan kepuasan hidup.

Dukungan keluarga merupakan informasi verbal, sasaran, bantuan yang nyata atau tingkah laku yang diberikan oleh orang-orang yang akrab dengan subjek didalam lingkungan sosialnya atau yang berupa kehadiran dan hal yang dapat memberikan keuntungan emosional atau pengaruh pada tingkah laku penerimaannya. Dalam hal ini 
orang yang merasa memperoleh dukungan sosial, secara emosional merasa lega diperhatikan, mendapat saran atau kesan yang menyenangkan pada dirinya, dukungan keluarga tersebut diperoleh dari individu maupun kelompok (Zainudin, 2002).

Hasil uji analisa bivariat menunjukkan ada hubungan antara dukungan keluarga dengan kualitas hidup penderita TBC di Kecamatan Selebar Kota Bengkulu dengan nilai $\mathrm{p}=0,03$. Penelitian sebelumnya tentang hubungan dukungan keluarga dengan kualitas hidup penderita DM tipe 2 menunjukkan ada hubungan yang signifikan antara dukungan keluarga baik emosional, informasional, instrumental dan penghargaan. Sebuah keluarga dengan tipe apapun harus memberikan dukungan kepada penderita untuk mencapai kualitas hidupnya (Aini Yusra, 2011).

Sejalan dengan penelitian Dwi Rahayu (2015) bahwa keluarga merupakan support sistem utama bagi penderita TBC dalam mempertahankan kesehatannya. Peranan keluarga dalam perawatan penderita antara lain: menjaga dan merawat penderita, mempertahankan dan meningkatkan status mental, mengantisipasi perubahan sosial ekonomi, memberikan motivasi/dukungan dan memfasilitasi kebutuhan spiritual penderita. Apabila dukungan keluarga tinggi maka akan menurunkan akan kesakitan dan kematian penderita. Juga hasil penelitian Hutapea Pengaruh dukungan keluarga terhadap kepatuan minum obat anti tuberkulosis menunjukkan adanya pengaruh dukungan keluarga teradap kepatuhan minum obat anti tuberkulosis, semakin tinggi dukungan keluarga semakin tinggi pula tingkat kepatuhan penderita minum obat OAT.

Hasil penelitian Siti Julaiha (2014) dari analisa bivariat dukungan keluarga dengan kualitas hidup klien TB menunjukkan ada hubungan yang signifikan pada domain $\mathrm{GH}$ $(\mathrm{p}=0,012)$ baik emosional, informasional, instrumental dan penilaian. Sebuah keluarga dengan tipe apapun harus memberikan dukungan kepada klien TB untuk mencapai kualitas hidupnya.

\section{KESIMPULAN}

Dari hasil penelitian dan pembahasan dapat ditarik beberapa kesimpulan bahwa sebagian besar kualitas hidup penderita TBC di Kecamatan Selebar Kota Bengkulu dengan kualitas tinggi baik skala fisik maupun skala mental dan terdapat hubungan yang signifikan antara dukungan keluarga dengan kualitas hidup penderita TBC di Kecamatan Selebar Kota Bengkulu.

\section{SARAN}

Kepada peneliti selanjutnya diharapkan agar berupaya lebih mengembangkan dan memperdalam bahasan tentang hubungan dukungan keluarga dengan kualitas hidup penderita TBC dengan menggunakan desain penelitian yang berbeda.

\section{DAFTAR PUSTAKA}

Aini Yusra (2011) Hubungan Antara Dukungan Keluarga Dengan Kualitas Hidup Pasien Diabetes Melitus Tipe 2 Di Poliklinik Penyakit Dalam Rumah Sakit Umum Pusat Fatmawati Jakarta. Universitas Indonesia. Jakarta.

Allender, J.A., Rector, C., \& Warner, K. D. (2014). Community Health Nursing : Promoting and Protecting the Public's Health. $8^{\text {th }}$ ed. Philadelpia: Lippincott Williams \& Wilkins.

Bredow, T., Peterson, S., \& Sandau, K. (2004). Middle-range theory: application to nursing research. 2nd ed. Philadelphia, PA: Lippincott Williams \& Wilkins.

Departemen Kesehatan Republik Indonesia. (2006). Pedoman Nasional Penanggulangan Tubrkulosis. Jakarta.

Direktorat Jendral Pengendalian Penyakit dan Penyehatan Lingkungan. (2011). Strategi Nasional Pengendalian TB di Indonesia 2010-2014, Kemenkes RI.

Departemen kesehatan RI. (2006). Pedoman

Penyelenggaraan Upaya Keperawatan Kesehatan Masyarakat di Puskesmas, 
Kepmenkes RI No. 279 tahun 2006. Jakarta.

Deribew, A., et.al. (2013). Change in Quality of Life : A Follow up Study among Patients with HIV Infection with and without TB in Ethiopia. BMC Public Health 13:408.

Fitria Sedjati (2013) Hubungan Antara Efikasi Diri Dan Dukungan Sosial Dengan Kebermaknaan Hidup Pada Penderita Tuberkulosis Paru Di Balai Pengobatan Penyakit Paru-Paru (BP4) Yogyakarta. Thesis, Universitas Ahmad Dahlan, Yogyakarta.

Friedman M.M, Bowden, V.R., Jones, E.G. (2003), Family Nursing, Research, Theory, and Practice. Edition, Philasdelphia : Printice Hall.

Friedman, M.M., Bowden, V.R., \& Jones, E.G. (2010). Buku ajar keperawatan keluarga: Riset, teori, dan praktik, alih bahasa, Akhir Yani S. Hamid dkk ; Ed 5. Jakarta: EGC

Hensarling, J. (2009). Development and psychometric testing of Henserling's diabetes family support scale, a dissertation. Degree of Doctor of Philosophy in the Graduate School of the Texa's Women's University

Guo, N., Marra, F., Marra, C. A. (2009). Measuring health-related quality of life in tuberculosis : a systematic review. Health Qual Life Outcomes. 7(14):1

Kemenkes RI, IDI. (2012). Panduan Tata Laksana Tuberkulosis sesuai ISTC dengan Strategi DOTS untuk Praktik Dokter Swasta (DPS). Jakarta

Kaakinen, Joana R, Gedaly-Duff, Vivian, et.al. (2010). Health Care Nursing : Theory, Practice \& Research. 4th edition. FA Davis Company: Philadelphia.

Louw, J., et.al., (2012). Quality of Life among Tuberculosis (TB), TB Retreatment and/or TB-HIV Co-infected Primary Public Health Care Patients in Three District in South Africa, Health Quality of Life Outcomes doi: 10.1186/14777525-10-77.
Maglaya, A.S. (2009). Nursing Practice in The Community. Fifth edition. Argonauta Corporation.

Masumoto, S., Yamamoto T., et.al. (2013). Factors Associated with Health- related Quality of Life among Pulmonary Tuberculosis Patients in Manila, the Philippines. Qual Life Res doi 10.1007/s11136-013-0571-x.

Novitasari, Indah Ayu (2014) Hubungan Antara Dukungan Keluarga Terhadap Konsep Diri Pada Penderita TBC Dalam Proses Pengobatan Di Wilayah Kerja Puskesmas Bendosari Sukoharjo. Thesis, Universitas Muhammadiyah Surakarta.

Nurlita Hendiani, dkk (2013) Hubungan Antara Persepsi Dukungan Keluarga Sebagai Pengawas Minum Obat Dan Efikasi Diri Penderita Tuberkolosis Di Bkpm Semarang. Thesis, Universitas Diponegoro, Semarang

Retni Ani dan Sugiyanto (2010) Hubungan Sosial Keluarga dengan Tingkat Kesembuhan Penderita Tuberculosis Paru di Puskesmas Umbulharjo II Yogyakarta. Thesis, STIKES Aisyiyah, Yogyakarta

SF-36.orghttp://www.sf 36.org/tools/sf8.shtml diakses tanggal 10 Maret 2018

Siti Julaeha (2014) Hubungan Karakteristik Klien Dan Pelaksanaan Tugas Kesehatan Keluarga dengan Kualitas Hidup Klien Tuberkulosis Paru di Kabupaten Pesawaran. Universitas Indonesia. Jakarta.

Sugiyono (2010). Metode Penelitian Kuantitatif Kualitatif dan R\&D. Jakarta.

World Health Organization. (2017) Global Tuberculosis Report 2017 http://www.who.int/tb/data diakses tgl 12 Maret 2017. 